\title{
Understanding Consumer Ethics in China's Demographic Shift and Social Reforms
}

\section{Wei-Fen Chen, Xue Wang, Haiyan Gao, Ying-yi Hong}

This is a post-review version that reflects suggested corrections but before any final publisher copy editing has taken place. 


\begin{abstract}
Purpose - The aim of this study is to explore some specific, current social phenomena in China that may influence consumers' ethical beliefs and practices, focusing on how some top-down, social and political changes could shape consumer behavior that needs to be understood in the Chinese context.
\end{abstract}

Design/Methodology/Approach-Extensive literature was critically reviewed to explore recent macro-societal reforms in China and their impact on consumers' (un)ethical practices.

Findings - We lay out how China, a government-led society, underwent a series of political reforms resulting in demographic shifts that differentiate it from its Western, industrialized counterparts. We connect these societal changes with Chinese characteristics to consumers' ethical evaluations, forming a new angle to understand consumer ethics in China. We also draw on two empirical examples to illustrate our argument.

Originality/Value - While consumer ethics are often explained by either cultural factors or individual variations, we discuss how one's ethical practice is shaped by one's social position, which is a product of national level public policy. Our discussions have ramifications for the study of consumers' social class and ethical practices because they take into account the elusive social positions and ambiguous social class consciousness of the Chinese population that have resulted from social mobility. Our discussions may give practitioners a better understanding of the ethical rationale behind consumers' changing lifestyles especially in the Chinese context.

Paper Type-General review

Keywords: China, Consumer ethics, Social stratification, Public policy

\title{
1. Introduction
}

Consumer ethics is an established theme in the study of consumer behavior in Western or industrialized countries (see the review of Vitell, 2003). In general, consumer ethics can be viewed as a response to business ethics, meaning that consumers may choose to purchase from firms and nations performing ethical practices, and to avoid purchasing from those doing the opposite (Belk et al., 2005). Consumer ethics may also be defined by consumers' own ethical behaviors and decisions in marketplace. The Muncy-Vitell scale of consumer ethics (see Vitell, 2015), for example, categorizes consumers' (un)ethical practices into five dimensions: "actively benefiting from illegal activities," "passively benefiting from someone else's mistake," "actively benefiting from questionable (but perceived to be legal) acts," "no harm/no foul," and "doing good/recycling." However, some new phenomenon in the emerging markets cannot be easily evaluated by such moral standards and their meanings may be better captured in the local context.

In the context of China, consumer ethics has been under-researched, and when researched, it often revolves around the "dark side" of unethical practices (e.g., bribery and other forms of corruption in China; Liu et al., 2017; Seidlmeier, 1999). Such a skewed perspective may reflect the lack of a local approach that grounds the discussion in the Chinese context, which has specific economic realities and social configurations that may be different from those in Western, industrialized countries. Since ethical judgments could be a product of local socioeconomic 
realities and cultural propensity, in this paper, we critically examine certain societal changes in China to demonstrate how they may shape consumers' particular ethical evaluations and practices.

China is the world's second largest economy (Barboza, 2010), as well as the largest consumer market worldwide (Ro, 2015). In the context of China's rapid economic development and social changes, consumers' (un)ethical practices may be a mixture of the cultural values they hold (values that are rooted in ancient Chinese philosophies, e.g., Confucianism, Taoism, and those that are commonly attributed to East Asian cultures, e.g., collectivism) and a reaction to current demographic changes and the enforcement of public policy. Given this context, the goal of this paper is twofold. First, we explore some current issues in China that are not often juxtaposed with the study of consumer ethics but that may in fact influence consumers' ethical practices. Second, we link these China-specific discussions with comparable socioeconomic realities in other emerging markets to explain why the new economic order has shaped consumers' ethical evaluations, which cannot be fully explained by existing accounts. We also illustrate the argument with two common "unethical" practices in China -- counterfeit consumption and guanxi-related ethics. This paper should be of interest to scholars and practitioners who seek to explore how individuals' values are affected by the recent macro-societal dynamics in China.

This paper supplements mainstream consumer ethics framework not simply because of its focus on China, a context that has been less explored, but in its connection to novel perspectives that are not often used to account for consumers' ethical practices. We focus on the politicaleconomic impact on consumer ethics, arguing that consumers' ethical judgments are not solely a cultural product, but rather an outcome of rapid position shifts in societal dynamics as well as in the global economy. As many social changes in China are discontinuous and abrupt, we believe such an approach may better explain those potential dynamics, and even ambivalence, in consumers' ethical judgments.

This paper is structured as follows. First, we lay out some "Chinese characteristics" in China's modernization process to discuss why they are significant to account for consumers' ethical practices. The discussions are divided into two parts. The first part mainly focuses on two demographic changes caused by social mobility: The emergence of a new middle class and ruralto-urban migration. In the second part, we further present how social policies affect individuals' daily lives as consumers. Subsequently, we present how the consumer ethics in other emerging markets may inform our discussions by drawing on two cases pertaining to consumer ethics in China and in other emerging markets: counterfeit consumption and guanxi-related ethics. Finally, we conclude the article with a diagram summarizing potential factors that may influence consumer ethics in China and how it interacts with the global market norms. We also suggest directions for future research.

\section{Recent demographic changes in China}

Compared with industrialized societies, where social structure is more influenced by market factors, initial endowment, and network structure ( $\mathrm{Li}, 1999)$, individuals' life opportunities in China are determined to a greater extent by the institutional arrangements of residential and employment opportunities (Zhou et al., 1997), persistent political power (Bian and Logan, 1996), and the role of government (Walder, 1995). In the post-1978 regime, economic forces have strengthened. Meanwhile, social policy and political power still influence the stratification 
process (Bian, 2002). As the social configuration in China has been changed by economic development and state policy, consumers' relative positions in a given society undergo dramatic mobility. Therefore, we may need a more dynamic view to understand social stratification by taking social mobility into consideration. As Shavitt, Jiang, and Cho (2016) point out, in the trend of widening income gap, people often gain or lose their socioeconomic status, which leads to questions regarding the applicability of insights based on static consumer segmentation (e.g., working class, middle class) as they do not reflect social position change across time.

We argue that, in China, there are at least two demographic shifts resulting from social mobility that may yield innovative insights for scholars and practitioners, namely, the emerging new middle class and rural-to-urban migration. In the following paragraphs, we first introduce the definition and pertinent research findings of social mobility. Then, we focus on the case of China and lay out how the new middle class representing upward mobility and the rural-to-urban migration representing horizontal mobility may serve as dynamic contexts for discussing consumers' ethical practices.

Social mobility refers to one's movement of relative position in a given society. It usually includes intra-generational and intergenerational social mobility. The former refers to one's social position movement compared to one's own past; the latter refers to one's movement compared to one's parents and is usually the focus of social mobility research (Sørensen, 1975). Intergenerational mobility is often measured by changes in income, occupation, and education between generations (e.g., Guo and Min, 2008; Grusky and Hauser, 1984).

Social mobility is a macro-societal shift that influences individuals' consumption. People within the same social class are expected to share common values, cultures, and lifestyles (Stephens et al., 2014). These particular values or cultures associated with social class are reflected in their consumption patterns. For example, the middle class, compared to their working class counterparts, tend to value uniqueness and to distinguish themselves from others in product selection (Stephens et al., 2007). However, individuals experiencing social mobility between classes may not naturally conform to the original class or adapt to the destination class. Instead, they may face challenges, experience inconsistent identities, and feel that they do not belong to any social classes (Friedman, 2014). For instance, compared to college students who have at least one parent with a four-year college degree, first-generation college students academically underperform because their interdependent propensity does not match the universities' expectation that students exercise independence (Stephens et al., 2012). Hence, the experience of moving up or down in the social hierarchy can cause uncertainty in one's status-based identity and further reduce well-being (Destin et al., 2017).

Even in the absence of actual social mobility, consumer behavior can be influenced simply by beliefs and expectations about social mobility. Expectations of great opportunities to move up on the social ladder can either increase or decrease consumption, depending on the purpose of consumption. When consumers focus on the high likelihood of narrowing the income gap, they consume less and save more. According to Yoon and Kim (2016), materialistic people who perceive high likelihood of economic mobility reduce their impulsive purchases in order to achieve long-term financial success. By contrast, if consumers focus on fierce competition from 
the same and close social tiers, perceived high social equality increases conspicuous consumption, especially within the lower class (Ordabayeva and Chandon, 2010).

In China, social mobility is closely related to two important social changes: The emerging new middle class and rural-to-urban migration, which are discussed below.

\subsection{The new middle class segment}

Since its 1978 economic reform and opening-up policy, China has experienced remarkable economic development, which has resulted in a burgeoning group of people who are classified as having a medium-level income. According to a 2013 report by the consulting firm McKinsey \& Company, by 2022 about 76 percent of urban households in China will be classified as middle class, with annual household incomes ranging from US\$9,000 to US\$34,000 (Barton et al., 2013). No consistent criteria exist, however, to define middle class in China (see Li, 2008). Some researchers use the integrated index of education, income, and occupation (e.g., Li and Zhang, 2008), while others emphasize income and purchasing power (e.g., Barton et al., 2013). The divergent definitions have resulted in different estimates of the size of the middle class. For example, Zhou's $(2005,2008)$ study based on 3,038 telephone interviews in five major cities in China indicates that $11.9 \%$ of the sampled city population belong to the middle class, as defined by their employment, education, and income. Meanwhile, according to the Global Wealth Report published in 2015 by Credit Suisse, $10.7 \%$ of the adults in China, or 109 million people, are middle class. A World Bank report (as cited in Kharas, 2010) indicates that the middle class in China is expected to increase to $70 \%$ of the total population in 2030 from just $12 \%$ in 2009 .

Regardless these variations in numbers, scholars consistently agree that a "new" middle class is emerging and that it implies lucrative business opportunities (Barton et al., 2013). Li (2011) summarized several consumption patterns of China's new middle class. First, compared with the lower class, they spend a lower percentage of their household incomes on basic needs (e.g., food, education, and healthcare) and a higher percentage on products to improve their quality of life (e.g., clothing, travel, and furniture). Specifically, the middle class spends only $60 \%$ of their household income on necessities (e.g., food and housing), while the lower class spends more than $80 \%$. Therefore, the new middle class has more disposable income and hence greater purchasing power for expensive products (e.g., cars) and long-term investments (e.g., supporting their children to study abroad). In addition, with abundant surplus incomes, the new middle class can invest in financial products and real estate. They also care more than the lower class about brands, product quality, and shopping experiences. Those born after the mid-1980s are a major group within the new middle class, and their consumption is expected to account for $35 \%$ of total urban consumption in 2022 (Barton et al., 2013).

China's new middle class is unique in that it subscribes to ideologies that are different from that of their Western or Asian counterparts. The distinction can be observed in at least the following three ways. First, a middle class is often regarded as a vital prerequisite to the development of democracy, a view that is supported by the social reforms that took place in Taiwan and South Korea (Li, 2010). However, according to a survey conducted in three major Chinese cities (Chen, 2013; Chen and Lu, 2011), the majority of the new middle class in China does not favor democracy; this is especially true among those employed in state-owned enterprises and those satisfied with their material conditions. Zhou (2010), an authoritative sociologist, characterizes 
the Chinese middle class as "the vanguard in consumption and the rear-guard in politics." As such, new middle class consumers may not be interested in certain ethical practices that are driven by liberal political stances. Therefore, although their consumption tastes are increasingly Westernized, the attitudes of these consumers toward Western consumer culture may still be ambivalent because they do not share the ideologies of liberty and a free economy.

Second, the new middle class may still subscribe to some traditional Chinese values. For example, according to recent research about how "face" influences consumption (Xia, 2017), the impact of face on luxury consumption is even stronger for young Chinese than for older generations. The finding suggests that traditional culture endures while the middle class expands. Doctoroff and Hong (2015) describe young Chinese consumers as "new minds in an old world," meaning that even though they take Western consumer goods and material enjoyment for granted, some deep Confucian cultural roots cannot be easily swept away. Their rationale for shopping could therefore be different from that of their Western counterparts.

Third, the self-identified middle class in China and the objectively defined middle class may not be one and the same. In a study conducted by Li and Zhang (2008), "middle class" is defined by income ( 1 to 2.5 times the average), occupation (managerial positions or those requiring technical skills), and education (college degree or above). This approach is an example of an objective way to define "middle class." In Li and Zhang's (2008) study, the “core (核心 he xin) middle class" match all three criteria for the definition of "middle class"; the "semi-core (半核心 ban he xin) middle class" match two criteria; while the "marginal (边缘 bian yuan) middle class" match only one criterion. However, these classifications do not correspond with the respondents' self-identified social positions. The same study revealed that only $61.7 \%$ of the core middle class, $53.5 \%$ of the semi-core middle class, and $46.8 \%$ of the marginal middle class identified themselves as middle class. Furthermore, $38.6 \%$ of those from other social classes identified themselves as middle class. Put differently, Chinese consumers have relatively ambiguous social class consciousness; that is, how they see themselves may be inconsistent with how they are defined according to commonly used, objective variables (i.e., income, education, and occupation).

Importantly, researchers found that self-identification of being middle class (subjective middle class perception) serves as a better predictor of perceived social justice than objective middle class measurement ( $\mathrm{Li}$ and Zhang, 2008). Therefore, while practitioners are accustomed to relying on social class to segment the market (Coleman, 1983), in China, they may need to look into consumers' self-claimed identities, in addition to commonly used, objective variables, to better predict consumer behavior. Even though some consumers are qualified to be middle class based on their income, education, and occupation, they may not respond to advertisements in the expected ways because of their self-identification.

\subsection{Rural-to-urban migration}

Urbanization is another wrenching change China has experienced since its economic reform and opening-up policy began in 1978. According to a 2015 report from China's National Bureau of Statistics, $56 \%$ of China's population live in urban areas and the number is still growing, compared with $49.7 \%$ in 2010 and only $20.9 \%$ in 1982 . The impact of urbanization on individuals is far-reaching. For example, the residential mobility that results from urbanization is 
believed to be the cause of changes in individuals' social relationships as well as their values and well-being (Oishi, 2010; Oishi and Talhelm, 2012). High movers reported less close social relationships and lower levels of well-being than lower movers (Oishi and Schimmack, 2010), but they are motivated to expand their social networks in order to avoid loneliness (Oishi et al., 2013). They also show higher preference for egalitarianism and individualism (Lun et al., 2012; Oishi and Kisling, 2009). Rural-born migrant households residing in urban areas report lower levels of happiness than rural households, possibly because of their new reference group, the urban-born residents (Knight and Gunatilaka, 2010).

These psychological features resulting from residential mobility inevitably affect how consumers shop. First, because residential mobility produces anxiety, people who move frequently seek a sense of familiarity and thus prefer shopping in familiar chain stores (Oishi et al., 2012). That being the case, while the need for uniqueness or novelty is regarded as an important drive for consumer behaviors in the West (Tian et al., 2001), its effect may be diluted in China due to the relationship between residential mobility and familiarity-seeking consumption (Oishi et al., 2012). Thus, in China, we argue that there is a potential market for consumer goods symbolizing interpersonal bonds, safety, and familiarity. For instance, established and familiar brands may have a greater likelihood of success in expanding their chain stores in locations with high migrant density rather than low migrant density. Also, established brands can better mitigate the risk of losing customers than less established brands can when they raise prices to implement ethical practices (e.g., Fair Trade).

Second, as urbanization has resulted in emerging metropolises in China, social comparison within concentrated populations becomes salient in the context of exacerbated economic inequality. Many studies have consistently demonstrated that individuals' relative position in society impacts their mental and physical health in vital ways. For example, some studies indicate that relative income compared to others predicts life satisfaction but objective income does not (Boyce et al., 2010; Luttmer, 2005). In addition, subjective socioeconomic status is a stronger predictor than objective socioeconomic status of psychological functioning and physical health (Adler et al., 2000; Cheon and Hong, 2017; Wang et al., 2016). An empirical study also suggests that affluent black South Africans purchase conspicuous products to catch up with the privileged white consumers they interacted with when growing up, suggesting that relative deprivation generates conspicuous consumption (Chipp et al., 2011). Similarly, the drastic rise in conspicuous consumption in post-Cultural Revolution China, especially in urban areas, is well documented (e.g., Podoshen et al., 2011). Factors such as traditional Chinese values (e.g., face; $\mathrm{Li}$ and $\mathrm{Su}, 2007$ ) and political ideology (e.g., Deng's policy of focusing on economic development; Sun et al., 2014) have often been used to explain the trends of emerging materialism and conspicuous consumption in China. We argue, however, that conspicuous consumption is also influenced by rapid urbanization, which leads to salient social comparison among individuals and may also lead to consumers' unethical practices simply out of a desire to "keep up with the Joneses."

Third, after migrating to big cities, many rural-to-urban migrants still try to keep their hukou in their rural hometowns. Previous studies usually criticize the constraints of the hukou system on migrant housing (Wu and Treiman, 2004; Logan et al., 2009), but some studies contend that many migrants are actually reluctant to give up their rural hukou even if they have a chance to do 
so because of great potential benefits tied to their rural hukou, such as receiving compensation for requisitioned land (e.g., Chen and Fan, 2016). Moreover, the way they deal with their rural homes reflects their aspirations for an urban lifestyle, such as adopting an "urban style" in their home décor (Zhang and Lin, 2014). Even though they are in their rural homes only for short periods of the year, they tend to build large houses furnished with high-end home appliances (Chen, 2003). While this may seem unnecessary and wasteful, they may be driven by a need to keep up in social comparison with others (Zhang and Lin, 2014); or a desire to signal their status when comparing themselves with people with urban hukou (Mazzocco, Rucker, Galinsky, and Anderson, 2012; Rucker and Galinsky, 2008).

Conversely, the hukou system and its related regulations are also changing the lifestyles of big city urbanites. For instance, some citizens living in big cities, such as Shanghai, intentionally manipulate their hukou information in order to have more people tied to the same hukou, so that more monetary compensation from the government can be expected when their houses need to be demolished for the purpose of urban development. Another example related to hukou is fake divorce. Specifically, Shanghai residents are required to make a 30\% down payment when purchasing their first home but must put down $70 \%$ for their second home, so many couples get a "fake" divorce so that one partner becomes the sole owner of their existing real estate, which allows the spouse to buy a new property as a first-time buyer. These couples then re-marry after the transaction (Wang, 2016). Such seemingly unethical practices have developed among urban residents as a way to get around the housing policy.

The demographic changes discussed above were mostly caused by national level public policy. In the following section, we discuss other public policies that have significantly impacted individuals' everyday lives, including their ethical practices.

\section{Public policy and consumption}

China has a long history and tradition of despotism and rule by authoritarian regimes (Walder, 1995; Wittfogel, 1956). Consumers' everyday lives are shaped by the government and by state power. Walder (1995) and Qiang Li (2008) argue that China is a "government-led society" in which the central government and local political agencies are the cause of many societal shifts at all levels, from politics to economy and culture. We review below how political forces have guided the recent social and cultural changes in China, and how they pertain to consumer ethics.

\subsection{The birth control policy}

China is one of a very few counties that has imposed a birth control policy on its citizens (Scharping, 2013). Enforcement of the one-child policy began in 1980 as a means to slow down China's population growth and to facilitate economic development (Wang et al., 2013). From the outset, the one-child policy was strictly enforced among urban residents, especially public sector workers, through penalties such as substantial fines and loss of employment (Hesketh et al., 2015). China also carried out large-scale sterilization and abortion campaigns. In 1983 alone, 14.4 million abortions, 20.7 million sterilizations, and 17.8 million intrauterine device insertions were performed, compared with approximately 21 million live births (Whyte et al., 2015). A large proportion of these medical procedures were involuntary. 
The one-child policy has had a huge impact on China's demographics. For instance, it has reduced the total fertility rate (TFR, the average number of children delivered by each woman) from 2.9 to 1.6, resulting in a recent labor shortage, as well as the most uneven gender ratio at birth, which peaked at 140 males to 100 females. This gender imbalance means men have great difficulty in finding a partner, resulting in a large number of unmarried men (Zhou et al., 2011). Such an imbalanced gender ratio may account for the emerging phenomenon of "mail-order brides," in which Chinese men pay agents to find them brides from less developed countries such as Vietnam, Laos, and Cambodia (Chow, 2017). For instance, a Chinese bachelor needs to pay as much as US \$18,500 to a Vietnamese marriage broker to “import" a wife (Minter, 2014). Although some mail-order brides volunteer to come to China, hoping to obtain Chinese citizenship and a better material life, many of them are tricked, coerced, or even sold to come to China, which is a gross violation of basic human rights (Thal, 2014). Therefore, the gender imbalance has been blamed for human trafficking, as well as other social problems such as high divorce rates and domestic violence (Chow, 2017).

On the positive side, the one-child policy has resulted in a healthier population (Li and Zhang, 2017), accelerated gender equality in education and the work place (Zhou et al., 2011), and accounted for a sharp increase in China's household savings (Choukhmane et al., 2013). That said, thirty-five years of the one-child policy also reshaped China's consumption-scape: the elder generation saved every penny to provide the best for their children, while the youngsters focus on a self-indulgent and self-fulfilling lifestyle (Yu, 2014). Research shows that the policy cultivated new behavioral patterns with less trust, less competition, more pessimism, more riskaversion, and less conscientiousness (Cameron et al., 2013). Moreover, even if the one-child policy implies more educational resources for each child, students are often burdened with their parents' excessive expectations and suffer from tremendous academic pressure, resulting in physical and psychological stress (Jing and Chen, 1995).

In order to alleviate problems caused by the one-child policy, the Chinese government implemented the two-child policy at the end of 2015, allowing all Chinese couples to have two children (Hesketh et al., 2015). The new policy is expected to increase population size, and thus mitigate problems in fertility, the work force, and economic development, which have been caused by aging population and the gender imbalance (Zeng and Hesketh, 2016). In 2016, the number of newborns rose to 17.86 million, an increase of 7.9 percent over 2015, according to China's National Health and Family Planning Commission. Such an increase once again affected individuals' purchasing behaviors, especially in the categories of real estate, baby products, and education. The two-child policy may also result in consumers' unethical practices. For instance, women who are over child-bearing age may try to avoid a high-risk pregnancy by hiring surrogate mothers on the black market (Sheng, Zhang, and Li, 2017). These examples demonstrate how public policy enforcement in China, often taking place without prior consultation and having a drastic impact on people's everyday lives, can have a trickle-down effect on consumption patterns and consumer ethics. That being the case, the state is able to drive and swing economic activities swiftly in China through changes in public policy, a marked contrast with the gradual changes resulting from market forces in the West.

\subsection{Wielding political capital in the post-reform era}


State power in China also permeates consumer culture. In recent years, a value change from thriftiness to hedonism has been observed, a shift that has taken place alongside the transition from a planned economy to a market economy (Wang, 2010). In the planned economy, the lifestyle of urban residents was locked at the level of basic living because of the government's minimum wage policy and rationing of basic living necessities ${ }^{1}$ (Wang, 2010). The values of self-discipline and thriftiness prevailed at that time, and the pursuit of a bourgeois, hedonic lifestyle was condemned. During the market reforms in the 1990s, however, economic development and GDP growth became the government's main, if not the sole, objective. At the policy level, the government sought to stimulate consumption and domestic demand, especially after the 2008 financial crisis (Newman, Rickert, and Schaap, 2011). As a result, Chinese cultural values and lifestyles were critically challenged, and that is reflected in the emerging Chinese consumer culture of hedonic consumption and materialism (Lin and Wang, 2010). Although improved economic conditions and the popular culture in the media may also have contributed to the formation of this new consumer culture (Pollay et al., 1990), state power and policy change are unquestionably among the most influential factors.

Bourdieu's (1986) discussion of various forms of capital is often employed by scholars to analyze how individuals compete for social status through consumption. That is, our consumption often reflects our possession of economic capital (financial resources such as money and assets), social capital (social networks such as relationships, organizations, and affiliations), and cultural capital (a set of socially rare and distinctive tastes, skills, knowledge, and practices) (Holt, 1998). However, consumption in China involves a fourth form of capital, political capital, which is often defined by membership in the Communist Party or by cadre status (Lin and Zhang, 2014). Needless to say, before the market reforms, political identity was especially important. During the transition from socialism to a market-oriented economy, these politically privileged individuals secured their advantageous positions through different mechanisms, such as strong information networks and connections with the government (Bian and Logan, 1996; Walder, 1996). Political power was salient especially in terms of consumption involving public resources and facilities, including access to housing, education, and health care (Castells, 1978).

Take housing as an example. The urban housing provision system in pre-reform China was an evidence of how state power produces housing inequality (Huang, 2003). Party members and individuals in powerful positions were able to manipulate housing allocation rules to favor their families (Djilas, 1957). In the post-reform era, the link between one's occupation and one's residential advantages has been weakened, while at the same time a new social stratum has arisen: Homeowners. The privatization of urban housing in 1998 allowed homeowners to capitalize upon their power and resources that were not evenly distributed in the pre-reform era and therefore expedited social inequality (Wu, 2002). These "new rich" homeowners may want to signal their superior economic status through hedonic and conspicuous consumption, abandoning the simple and frugal lifestyle promoted by the party in the pre-reform era.

\footnotetext{
${ }^{1}$ This policy is enforced through the distribution of Basic Living Voucher (基本生活资料的凭证定额供应 Ji Ben Sheng Huo Zi Liao De Ping Zheng Ding E Gong Ying), which is needed to have a quota to purchase necessities at affordable prices determined by the government. The restricted product types include grains, eggs, sugar, cooking oil, etc.
} 


\section{Rethinking consumer ethics in China and other emerging markets: Two examples}

We have discussed above the macro-societal forces in China, including the expansion of new middle class, rapid urbanization, and strong enforcement of public policies (birth control, homeownership), all of which have resulted in swift socio-economic changes. These characteristics have created contradictions between traditional values and new cultures, rural and urban lifestyles, and the "haves" and "have-nots." We also lay out how state power and political capital remain significant in the post-reform, market-oriented economy, and how market demands usually acutely reflect consumers' lifestyle changes brought by shifting public policies. For example, an individual's choice of his/her dwelling may not be a personal discretionary decision but rather one that has been pre-determined by the hukou system, the compulsory registration of residences. Therefore, rural-to-urban migrants may constantly experience a sense of being excluded and thus feel a need to create an upper-class façade so as to fit in. While living beyond one's means can be considered unethical, for Chinese migrants, this tendency is a way to cope with their perceived inferior status which was determined by the institutionalized power.

In this section, the discussions of consumer ethics in China are informed by other emerging markets in the world. We argue that, consumer ethics is influenced not only by individuals' social position shifts in the local society, but also by the whole country's status change in the global economy. In this view, Chinese consumers may share similar psychological features with their counterparts in other emerging markets, because their countries are undergoing economic development to different extents. In the following paragraph, we draw on literature that is pertinent to emerging markets to discuss how these trends and features documented may facilitate the understanding of consumer ethics in China. Specifically, we use two empirical examples to illustrate how consumer ethics in China, just like in other emerging markets, is shaped by the country's dynamic status on its way to become a key player in the global market.

\subsection{Consumer ethics in the emerging market context}

Previously the consumer ethics in the emerging markets were often discussed from the perspective of how emerging market consumers and their Western counterparts may subscribe to different ethical beliefs because of cultural differences. However, scholars are still debating the extent to which consumers' ethical beliefs and practices vary substantially across cultures. On the one hand, for example, Rawwas et al. (2005) argue that, compared with American consumers, Turkish consumers are more likely to avoid uncertainties (one of Hofstede's cultural dimensions). Therefore, when they make a mistake in the grocery store (such as breaking an item), they may need more guidance and assistance with regard to what to do next, otherwise they may stop their shopping to avoid uncertainties and may perceive the store environment to be unfriendly (Rawwas et al., 2005). Swaidan (2012) also employs Hofstede's model of cultural dimensions to argue that consumers who subscribe to different cultural orientations tend to have different ethical beliefs. He found that consumers who score high in collectivism, high in uncertainty avoidance, low in masculinity, and low in power distance reject illegal, and active or passive questionable activities more than consumers who score low in collectivism, low in uncertainty avoidance, high in masculinity, and high in power distance. On the other hand, though, the research of Belk et al. (2005) shows a general lack of evidence that consumers across cultures care differently about specific ethical issues. With subjects from eight countries on different continents, their study concluded that culture does not influence consumers' 
justifications and ethical stands as much as they expected. For these consumers, unethical business practices are simply "the way of the world," and their cultural backgrounds were not a precise indicator for predicting their future ethical purchases.

Scholars' divergent perspectives aside, this kind of analytic framework of cultural typology may risk replicating a static worldview. Among the studies that attempt to examine the rationales behind consumers' (un)ethical practices in the emerging markets, relatively few are grounded in the local socioeconomic realities. To fill this knowledge gap, we examine two common "unethical" issues that are observed in China, and discuss their implications under China's status as an emerging market, where historical, cultural, and economic shifts are taking place. The two examples are counterfeit consumption and guanxi-related ethics.

\subsection{Counterfeit consumption}

The intentional purchase of counterfeit goods has often been considered an unethical consumer behavior (Shepard, 2017). Kwong et al. (2009) contend that Chinese consumers purchase more counterfeits than their Western counterparts because these two groups of consumers have different views on social costs, social benefits, and big business. It is also common to associate the status consumption of Chinese consumers (i.e., using counterfeits to signal social status) with the Confucian collectivist cultural tradition, in which conspicuous and valuable possessions (e.g., jewelry) are needed to concretely demonstrate and communicate financial achievement, a central concern in the social hierarchy (Wong and Ahuvia, 1998). However, recent studies conducted in other emerging markets can inform these conventional discourses, such as in the case of Turkey, where counterfeit usage is associated more with Turkey's transitional status as an emerging market in the global economy, than with local traditional culture.

Kravets and Sandikci (2014) argue that some Turkish consumers purchase counterfeits because they believe that they have been excluded from the global consumer society, and that the product and price they have in the "less developed" Turkish market are different from those in the industrialized, leading markets. In their study, some informants purchased counterfeits because "the counterfeits are available before originals and are of similar quality because originals are submanufactured in Turkey" (p.135). Similarly, for Chinese consumers, buying counterfeits could mean more than using conspicuous consumption to signal social status. Drawing on the example of Turkish consumers, the purchase of counterfeits may reflect an ambivalent identity when emerging market consumers are "half way" to being international shoppers in the contemporary consumer society. Although they are informed of global trends via worldwide information flow such as the popular media, consumers at the same time realize that their country is treated as a laggard in the global distribution system. Hence, their "unethical" purchase of counterfeits could be based on an "ethical" pursuit to claim full, equal citizenship in the global economic order.

This tendency is revealed not only in the cross-country comparison but also in studies focusing on domestic markets. Tang et al. (2014) found that some Chinese students purchase counterfeits with the motivation of undermining the unequal relationship between manufacturers and consumers, as the former has asymmetrically stronger power over the latter. Some young consumers believe that this is a way to fight unethical monopolies, such as buying pirated Microsoft software because the originals are overpriced and there are hardly any alternative 
options (Tang et al., 2014). Rawlinson and Lupton (2007) also contend that Chinese students, compared to their American counterparts, tend to believe the control of pirated software usage is the instructor's responsibility. In other words, Chinese students may not see themselves using such software as a significant problem unless it is regulated by the authority. In a similar vein, Chiou, Huang, and Lee (2005) indicate that consumers access pirated music because copyrighted music products are considered overpriced and the serious consequences of such behaviors are often neglected. Specifically, how consumers perceive the magnitude of consequence and social consensus affects their attitude to music piracy. In such scenarios, consumers do not consider their counterfeit purchase unethical because their behavior does not hurt any ethical entities and may even help create a fairer market. Thus, consumers may keep using counterfeits until they are strictly banned.

Such justification can also be observed in the "counterfeit" consumption in the field of digital culture, such as the case of fansub. Fansub, short for fan subtitling, is a particular type of noncommercial, non-institutionalized, informal, voluntary, organized translation done by a group of fans who are interested in foreign popular culture (such as Japanese animations, American television series, and Korean dramas) and are equipped with the language proficiency to understand the foreign media content (Tian, 2011). These fans work as a group to reproduce the foreign media content with Chinese subtitles that they have translated, and then they distribute in near-real time these new versions online for free "to provide nationwide fans with the most authentic experience of foreign culture that due to the strict governmental media regulation could not have been easily accessed through legitimate channels" (Tian, 2011, p.2). These fans are consumers as well as, to a certain extent, producers. They challenge censorship in China and infringe on the copyright of the foreign content providers, so their behavior can easily be categorized as an unethical act. It can be argued as another form of counterfeit consumption, because people access contents that are not "authentic" and should not have been available to them.

These acts seldom bring any monetary benefits to either the translators themselves or a specific group, but when it comes to their cultural influence, scholarly discussion and popular media discourse tend to echo the "anonymous heroes" moniker for fansubbers by acknowledging their altruistic sharing that introduces local consumers to exotic cultural forms (Wei, 2016; Zhang, 2013). The same viewpoint is also adopted by the fansubbers themselves to legitimize their questionable behavior, as they believe that they have empowered audiences for the public good (Hsiao, 2014). The subtitling is an extension of their thirst for various cultural forms and fine media content (French, 2006; Wei, 2016). Their endeavors facilitate the spread of foreign cultures in China, and subsequently create business opportunities for foreign media companies (e.g., gaming, animation) because the materials are already familiar to Chinese consumers (Wei, 2016).

The premise of fansub is that the emerging market consumers have developed a more cosmopolitan taste even if they can only legally consume a small, filtered part of foreign cultural forms that does not completely represent the rest of the world. Such unethical acts could be altruistic in nature, aiming to introduce local consumers to exotic cultural forms. Just like how people may shop for counterfeits for a good cause of equality across markets, fansub can also be viewed as an act to get around censorship and access filtered information. 


\subsection{Guanxi-related ethics}

Guanxi, literally meaning interpersonal connections and relationships, is deeply rooted in traditional Chinese culture (Su et al., 2003; Dunning and Kim, 2007). Yet, its practice in day-today life and in commerce can be confusing to outsiders. Westerners may find it difficult to differentiate between guanxi and bribery or other forms of corruption, especially when giftgiving is involved to nurture guanxi and certain social obligations are imposed upon both the receiver and the giver (Steidlmeier, 1999; Su et al., 2001). At the root of guanxi is renqing, which has been suggested as being the underlying mechanism that guides the behavioral norms of guanxi. Renqing often refers to the exchange of favors, in accordance with certain social norms and behavioral rules (e.g., giving expensive gifts, such as gold jewelry, at weddings) that are especially important in rural society (Hwang, 1987).

In general, guanxi is utilitarian, reciprocal, transferable, personal, long-term, and intangible in nature (Dunning and Kim, 2007), and it can be divided into two kinds. "Favor-seeking guanxi is culturally rooted signifying social contracts and interpersonal exchange of resources in a collectivistic society. Rent-seeking guanxi reflects on institutional norms signifying social collusion based on power exchange in a hybrid Chinese socialist market economy" (Su et al., 2003, p.310). Since rent-seeking guanxi implies giving and receiving favors in the bureaucratic system, it is associated with corruption more than favor-seeking guanxi is.

The unavoidable practice of guanxi is often perceived as a characteristic of the Chinese market, where business does not yet operate according to institutionalized rules and regulations (Warren et al., 2004). With little assistance and few official or legitimate solutions, guidelines, and resources, individuals may find it necessary to establish guanxi with bureaucratic power (Warren et al., 2004). However, while the prevailing assumption is that guanxi can only be challenged by external, non-Chinese forces such as Western, transnational firms, we argue that guanxi could be undermined by recent dynamics within the Chinese society.

Guanxi may be viewed as a form of social capital, i.e., the association with social networks such as relationships, organizations, and affiliations (Bourdieu, 1986). For example, some may have strong social capital to get access to insider information from the "right people" in order to deal with issues in a local community, such as gaining access to private schools. We may assume that the elites have stronger and more useful social capital than the general population. However, previous studies have suggested that individuals' capital operates differently outside the context where the capital was first developed. Owens (2015) indicates that in the housing crisis during the Great Recession, some advantageous characteristics of the middle class became disadvantages in the mortgage modification process when compared with their working class counterparts (Owens, 2015). Working class homeowners may have a more useful social network with similar others that enabled them to quickly share key information to avoid scams and facilitate applications.

Owens' (2015) study implies that a strong, fixed, and compact guanxi network may no longer work well in the context of the socioeconomic shifts in China today. At the national level, China has gradually become the regional leader, for instance, through the recently launched one-beltone-road initiative that seeks to facilitate cooperation among countries in Europe, Africa, and 
Asia. At the organizational level, more China-originated companies have tapped into the global market and become transnational corporations. At the individual level, more Chinese citizens have acquired international experiences, either through short-term overseas tourism or long-term education abroad. In other words, in contrast with Western firms that attempt to figure out guanxi, Chinese entities may be even more motivated to gain a new sensibility of the ethical climate that is recognized worldwide. That is to say, on the one hand, unstable socioeconomic conditions may result in corruption, but on the other hand, the globalized development of China may weaken traditional social ties, which to a large extent dictate everyday interaction and business relationships. This duality is reflected in China where, on the one hand, the Chinese government has recently launched high profile crackdowns on corrupt officials, while on the other hand, petty "bribery" (e.g., giving "red pocket money" to physicians in charge of surgery) is still tolerated and prevalent in the lives of ordinary people (Liu et al., 2017).

To sum up, societal developments in the emerging markets have ramifications for the interpretation of consumer ethics in China. Furthermore, it enriches our understanding of the rationales behind consumers' (un)ethical practices in China and other emerging markets. Our insight into consumer ethics can be enriched if we take the local socioeconomic realities into consideration. Scholars may want to focus on how emerging market consumers' ethical practices are co-constituted by the changing glocal consumer society as well as the extent to which the consumers appropriate the implications of such a dynamic process.

\section{Conclusion and future directions}

This paper has reviewed and discussed how recent macro-societal reforms in China interact with traditional Chinese culture to shape Chinese consumers' behaviors and consumption ethics. Consumer ethics in China is shaped by individuals' responses to rapid socio-economic changes and coercive public policies. It is also influenced by China's status as an emerging market, so that some features of Chinese consumer ethics are comparable to the trends in other emerging markets. That being the case, we cannot fully understand consumers' ethical choices without considering their position in the social configuration and in the world economy, as well as the interplay among socio-political changes and cultural values and traditions. Figure 1 visualizes the relationship among multiple variables that were argued to affect consumer ethics in China. Local characteristics were co-constituted by political power, economic reform, and traditional culture. Meanwhile, these local characteristics inform, and also being informed, by the aspired global standards and norms that are perceived to represent advanced economies. As such, a local approach that grounds the discussion in the Chinese context holds ramifications for the mainstream account of consumer ethics.

\section{[Insert Figure 1 here]}

Although rapid and abrupt social changes can sometimes become obstacles when promoting ethical practices among consumers, the changes could also be turned into potential opportunities for entrepreneurs whose aim is to create innovative solutions to address the demands of the largest consumer market in the world. For example, to deal with the overflow population in megacities, policy makers and practitioners struggle to create employment opportunities and improved living conditions in the countryside in order to motivate youngsters to stay near their birth places. One of the solutions to this issue is e-commerce. The Chinese online retailing giant 
Taobao collaborates with around 1,000 local, small shops in rural areas that they call "Taobao villages," which serve as the commercial hubs and pick-up locations for rural consumers who have placed an order online (Weller, 2017). This type of arrangement reduces door-to-door delivery costs and brings business opportunities to the local shops, which earn profits from goods storage as well as consumers' additional, unplanned shopping when they come to pick up their orders in the store (Chu, 2016). In addition, by utilizing big data, consumers' demands can be predicted even before they actually place an order. Products can be packed and shipped in advance to the local shops to await the anticipated consumers (Chu, 2016). In this way, local consumers enjoy convenience and variety in product selection as much as urbanites do. This business strategy not only solves the "last mile" problem of delivery, but also empowers some poor, rural communities, and eventually facilitates a more balanced development across various regions in China (Weller, 2017). It may trigger social behavioral change downstream as well. For instance, according to Winterich and Zhang (2014), consumers may reduce their ethical, prosocial behaviors (e.g., charitable donations) if they perceive high power distance and social inequality. This suggests that even if Chinese consumers have more disposable incomes, they may not feel obligated to engage in altruistic, ethical practices if they believe in an unequal society (Winterich and Zhang, 2014). Therefore, as Taobao villages bridge the rural-urban gap, and thus empower rural consumers, they may also further reduce consumers' unethical practices because they alleviate relative deprivation and perceived inequality.

Extrapolating from this study, we suggest two directions for future research.

First, if we approach consumer ethics issues solely as a cultural phenomenon or a product of personal belief without considering socioeconomic forces, it leaves relatively little room for scholars to suggest solutions to correct unethical practices. In this paper, we discuss consumer ethics through the lens of individuals' choices to accommodate to socioeconomic shifts, implying that consumers' perceived or experienced inequality may relate to their agency in making ethical choices. While we argue how multiple forces have separately influenced consumer ethics, these forces can also be viewed as factors that may interact with one another to shape consumer ethics. For example, given that China is among the countries with the highest Gini coefficient (Xie and Zhou, 2014), the drastic contrast between the poor and the rich may result in different reactions to demographic shifts and public policy across these two groups, and the poor may be more susceptible to social mobility changes (Yoon and Kim, 2017). We encourage future studies to continue looking at how people's socioeconomic status and their corresponding psychological states may moderate how they interpret, react, and cope with changes in public policy. Future studies may also consider empirically examining how consumers' perceptions of social position, either in the domestic scope or in the global market, affect their (un)ethical practices. This kind of empirical evidence can inform public policy and business strategies that aim to build a more socially responsible and sustainable marketplace.

Second, we urge more scholars to explore consumer ethics in China from its transitional status as an emerging market or as a modern society where consumers have cultivated a globalized taste, instead of from its traditional, old cultural form. This "transitional status" perspective allows scholars to scrutinize the complexities of the Chinese market, such as the division between welldeveloped cities and developing rural areas. In terms of consumer ethics, urban populations could be overrepresented in scholarly discussions since they are capable consumers with strong purchasing power. In contrast, rural consumers and migrant workers are often ignored. A 
political-economy approach may yield a more complete conceptualization of consumer ethics across various market segments. Furthermore, examining the Chinese market based on its transitional status also requires adding other comparison groups in multiple levels of development. Future research comparing China with other developing countries and capitalist societies will bring interesting insights to how a country's participation in the global market influences its consumers' particular ethical interpretations and coping strategies.

\section{References}

Adler, N.E., Epel, E.S., Castellazzo, G. and Ickovics, J.R. (2000), "Relationship of subjective and objective social status with psychological and physiological functioning: preliminary data in healthy, White women", Health Psychology, Vol. 19 No. 6, pp. 586-592.

Barboza, D. (2010), "China passes Japan as second-largest economy”, available http://www. nytimes.com/2010/08/16/business/global/16yuan.html?pagewanted=all (Accessed 3 October).

Barton, D., Chen, Y. and Jin, A. (2013), “Mapping China's middle class”, McKinsey Quarterly, Vol. 3, pp. 54-60.

Belk, R.W., Devinney, T. and Eckhardt, G. (2005), “Consumer ethics across cultures”, Consumption Markets \& Culture, Vol. 8 No. 3, pp. 275-289.

Bian, Y. (2002), "Chinese social stratification and social mobility”, Annual Review of Sociology, Vol. 28 No. 1, pp. 91-116.

Bian, Y. and Logan, J.R. (1996), "Market transition and the persistence of power: The changing stratification system in urban China", American Sociological Review, Vol. 61 No. 5, pp. 739-758.

Bourdieu, P. (1986), "The forms of capital", in Richardson, J. G. (Ed.), Handbook of Theory and Research for the Sociology of Education, Greenwood Publishing Group, New York, NY, pp. 241-258.

Boyce, C.J., Brown, G.D. and Moore, S.C. (2010), "Money and happiness: rank of income, not income, affects life satisfaction", Psychological Science, Vol. 21 No. 4, pp. 471-475.

Cameron, L., Erkal, N., Gangadharan, L. and Meng, X. (2013), “Little emperors: behavioral impacts of China's one-child policy”, Science, Vol. 339 No. 6122, pp. 953-957.

Castells, M. (1978), “City, class and power”, in City, Class and Power, Springer, Macmillan Education UK., pp. 167-173.

Chen, X. (2003), 救赎与消费: 当代中国日常生活中的消费主义: 消费主义, 一种新型的权力 支配, 江苏人民出版社, Nanjing, China.

Chen, C. and Fan, C.C. (2016), “China's hukou puzzle: why don't rural migrants want urban hukou?” China Review, Vol. 16 No. 3, pp. 9-39. 
Chen, J. (2013), A Middle Class Without Democracy: Economic Growth and the Prospects for Democratization in China, Oxford University Press, Oxford.

Chen, J. and Lu, C. (2011), "Democratization and the middle class in China: the middle class's attitudes toward democracy", Political Research Quarterly, Vol. 64 No. 3, pp. 705-719.

Cheon, B.K. and Hong, Y. (2017), "Mere experience of low subjective socioeconomic status stimulates appetite and food intake", Proceedings of the National Academy of Sciences, Vol. 114 No. 1, pp. $72-77$.

Chiou, J., Huang, C., and Lee, H. (2005), "The antecedents of music piracy attitudes and intentions", Journal of Business Ethics, Vol. 57 No.2, pp. 161-174.

Chipp, K., Kleyn, N. and Manzi, T. (2011), "Catch up and keep up: relative deprivation and conspicuous consumption in an emerging market", Journal of International Consumer Marketing, Vol. 23 No. 2, pp. 117-134.

Choukhmane, T., Coeurdacier, N. and Jin, K. (2013), "The one-child policy and household savings", CEPR Discussion Paper No. DP9688, available at: https://ssrn.com/abstract= 2341051 (Accessed 5 October 2017)

Chow, E.K. (2017), “China's trafficked brides”, available at: http://thediplomat.com/2017/07/ chinas-trafficked-brides/ 9 (accessed 27 September 2017).

Chu, Z. (2016), “馬雲的「菜鳥」知道你要什麼”, available at: http://www.cw.com.tw/article/ article.action? id=5078568 (Accessed 3 October 2017).

Coleman, R.P. (1983), "The continuing significance of social class to marketing”, Journal of Consumer Research, Vol. 10 No. 3, pp. 265-280.

Destin, M., Rheinschmidt-Same, M. and Richeson, J.A. (2017), "Status-based identity: a conceptual approach integrating the social psychological study of socioeconomic status and identity", Perspectives on Psychological Science, Vol. 12 No. 2, pp. 270-289.

Djilas, M. (1957), The New Class: An Analysis of The Communist System, Praeger.

Doctoroff, T. and Hong, L.Y. (2015), "Chinese millennials: new minds in an old world", available at: https://www.bloomberg.com/view/articles/2014-12-25/china-needs-millionsof-brides-asap (accessed 29 September 2017).

Dunning, J.H. and Kim, C. (2007), "The cultural roots of Guanxi: An exploratory study", The World Economy, Vol. 30 No. 2 pp. 329-341.

French, H.W. (2006), "Chinese tech buffs slake thirst for U.S. TV shows", available at: http://www.nytimes.com/2006/08/09/world/asia/09china.html (Accessed 3 October 2017).

Friedman, S. (2014), "The price of the ticket: rethinking the experience of social mobility", Sociology, Vol. 48 No. 2, pp. 352-368. 
Grusky, D.B. and Hauser, R.M. (1984), "Comparative social mobility revisited: models of convergence and divergence in 16 countries", American Sociological Review, Vol. 49 No. 1, pp. 19-38.

Guo, C. and Min, W. (2008), "Education and intergenerational income mobility in urban China", Frontiers of Education in China, Vol. 3 No. 1, pp. 22-44.

Hesketh, T., Zhou, X. and Wang, Y. (2015), "The end of the one-child policy: lasting implications for China”, Jama, Vol. 314 No. 24, pp. 2619-2620.

Holt, D.B. (1998), “Does cultural capital structure American consumption?” Journal of Consumer Research, Vol. 25 No. 1, pp.1-25.

Hsiao, C. (2014), "The moralities of intellectual property: Subtitle groups as cultural brokers in China”, The Asia Pacific Journal of Anthropology, Vol. 15 No. 3, pp. 218-241.

Huang, Y. (2003), "Renters' housing behaviour in transitional urban China", Housing Studies, Vol. 18 No.1, pp. 103-126.

Hwang, K. K. (1987), "Face and favor: The Chinese power game", The American Journal of Sociology, Vol.92 No.4, pp. 944-974.

Kharas, H. (2010), "The emerging middle class in developing countries", working paper No. 285, OECD Development Centre, France, January 2010.

Knight, J. and Gunatilaka, R. (2010), "Great expectations? The subjective well-being of ruralurban migrants in China", World Development, Vol. 38 No. 1, pp. 113-124.

Kravets, O. and Sandikci, O. (2014), "Competently ordinary: New middle class consumers in the emerging markets", Journal of Marketing, Vol. 78 No. 4 pp. 125-140

Kwong, K.K., Yu, W.Y.P., Leung, J.W.K. and Wang, K. (2009), "Attitude toward counterfeits and ethnic groups: Comparing Chinese and Western consumers purchasing counterfeits", Journal of Euro-marketing, Vol. 18 No. 3 pp. 157-168

Li, C., (2008), “中国中产阶级的增长及其现状”, 江苏社会科学, Vol. 5, pp. 68-77.

Li, C. (Ed.) (2010), China's Emerging Middle Class: Beyond Economic Transformation, Brookings Institution Press, Washington, DC.

Li, C., (2011), “中产阶级的消费水平和消费方式”, 广东社会科学, Vol. 4, pp. 210-218.

Li, Q. (1999), “中国大陆城市农民工的职业流动”, 社会学研究, Vol. 3, pp. 93-101.

Li, Q. (2008), “试分析国家政策影响社会分层结构的具体机制”, 社会, Vol. 28 No. 3, pp. 5464.

Li, J.J. and Su, C. (2007), "How face influences consumption", International Journal of Market Research, Vol. 49 No. 2, pp. 237-256. 
Li, P.L. and Zhang Y. (2008), “中国中产阶级的规模, 认同和社会态度”, 社会, Vol. 28 No. 2, pp. 1-1.

Li, B. and Zhang, H. (2017), "Does population control lead to better child quality? Evidence from China's one-child policy enforcement", Journal of Comparative Economics, Vol. 45 No. 2, pp.246-260.

Lin, X. and Wang, C. L. (2010), "The heterogeneity of Chinese consumer values: a dual structure explanation”, Cross Cultural Management: An International Journal, Vol. 17 No.3, pp. 244-256.

Lin, X. and Zhang Y. (2014), “制度变迁与消费分层: 消费不平等的一个分析视角”, 兰州大 学学报 (社会科学版), Vol. 42 No. 1, pp. 8-15.

Liu, Z., Liu, X., Hong, Y., Brockner, J., Tam, K., \& Li, Y. (2017), "Is individual bribery or organizational bribery more intolerable in China (versus in the United States)? Advancing Theory on the Perception of Corrupt Acts", Organizational Behavior and Human Decision Processes, doi: 10.1016/j.obhdp.2016.12.002

Logan, J.R., Fang, Y. and Zhang, Z. (2009), “Access to housing in urban China”, International Journal of Urban and Regional Research, Vol. 33 No.4, pp. 914-935.

Lun, J., Oishi, S. and Tenney, E.R. (2012), "Residential mobility moderates preferences for egalitarian versus loyal helpers", Journal of Experimental Social Psychology, Vol. 48 No. 1, pp. 291-297.

Luttmer, E.F. (2005), "Neighbors as negatives: relative earnings and well-being", The Quarterly Journal of Economics, Vol. 120 No. 3, pp. 963-1002.

Jing, L. and Chen Q. (1995), “Academic pressure and impact on students' development in China", McGill Journal of Education, Vol. 30 No.2, pp.149-168.

Mazzocco, P.J., Rucker, D.D., Galinsky, A.D., and Anderson, E.T. (2012), "Direct and vicarious conspicuous consumption: Identification with low-status groups increases the desire for high-status goods", Journal of Consumer Psychology, Vol. 22 No. 4, pp. 520-528.

Minter, A. (2014), "China's fraudulent mail-order wife scandal is only the start of a much larger problem", available at: https://www.bloomberg.com/view/articles/2014-12-25/chinaneeds-millions-of-brides-asap (accessed 27 September 2017).

Newman, S., Rickert C. and Schaap R.D. (2011), "The globe: investing in the post-recession world", available at: https://hbr.org/2011/01/the-globe-investing-in-the-post-recessionworld (accessed 22 September 2017].

Oishi, S. (2010), "The psychology of residential mobility: Implications for the self, social relationships, and well-being", Perspectives on Psychological Science, Vol. 5 No. 1, pp. $5-21$. 
Oishi, S., Kesebir, S., Miao, F.F., Talhelm, T., Endo, Y., Uchida, Y., ... and Norasakkunkit, V. (2013), "Residential mobility increases motivation to expand social network: but why?", Journal of Experimental Social Psychology, Vol. 49 No. 2, pp. 217-223.

Oishi, S. and Kisling, J. (2009), "The mutual constitution of residential mobility and individualism”, in Wyer, R.S., Chiu C.Y. and Hong Y. (Eds.), Understanding Culture: Theory, Research, and Application, Psychology Press, New York, NY, pp. 223-238.

Oishi, S., Miao, F.F., Koo, M., Kisling, J. and Ratliff, K.A. (2012), "Residential mobility breeds familiarity-seeking", Journal of Personality and Social Psychology, Vol. 102 No. 1, 149162.

Oishi, S. and Schimmack, U. (2010), "Residential mobility, well-being, and mortality", Journal of Personality and Social Psychology, Vol. 98 No. 6, pp. 980-994.

Oishi, S. and Talhelm, T. (2012), "Residential mobility: what psychological research reveals", Current Directions in Psychological Science, Vol. 21 No. 6, pp. 425-430.

Ordabayeva, N. and Chandon, P. (2010), "Getting ahead of the Joneses: when equality increases conspicuous consumption among bottom-tier consumers", Journal of Consumer Research, Vol. 38 No. 1, pp. 27-41.

Owens, L.A. (2015), "Intrinsically Advantageous? Reexamining the Production of Class Advantage in the Case of Home Mortgage Modification", Social Forces, Vol. 93 No. 3 pp. 1185- 1209.

Podoshen, J.S., Li, L. and Zhang, J. (2011), "Materialism and conspicuous consumption in China: a cross-cultural examination", International Journal of Consumer Studies, Vol. 35 No. 1, pp. 17-25.

Pollay, R.W. and Gallagher, K. (1990), "Advertising and cultural values: Reflections in the distorted mirror”, International Journal of Advertising, Vol. 9 No.4, pp. 359-372.

Rawlinson, D. R. and Lupton, R. A. (2007), "Cross-national attitudes and perceptions concerning software piracy: A comparative study of students from the United States and China", Journal of Education for Business, Vol. 83 No.2 pp.87-94.

Rawwas, M.Y.A., Swaidan, Z. and Oyman, M. (2005), "Consumer ethics: A cross-cultural study of the ethical beliefs of Turkish and American consumers", Journal of Business Ethics, Vol. 57 No. 2 pp. 183-195.

Ro, S. (2015), "China is the world's largest consumer of most commodities", available at: http://www.businessinsider.com/chinas-share-of-global-commodity-consumption-2015-8 (Accessed 3 October 2017).

Rucker, D. D. and Galinsky, A. D. (2008), "Desire to acquire: Powerlessness and compensatory consumption”, Journal of Consumer Research, Vol. 35 No.2 pp.257-267. 
Scharping, T. (2013), Birth Control in China 1949-2000: Population Policy and Demographic Development. Routledge.

Shavitt, S., Jiang, D., and Cho, H. (2016), "Stratification and segmentation: Social class in consumer behavior”, Journal of Consumer Psychology, Vol. 26 No.4 pp.583-593.

Sheng M., Zhang C. and Li, R. (2017), "Chinese couples desperate for children turn to illegal surrogacy", available at: http://www.caixinglobal.com/2017-05-30/101095787.html (accessed 22 September 2017).

Shepard, W. (2017), "How Chinese counterfeiters continue beating Amazon", available at: https://www.forbes.com/sites/wadeshepard/2017/01/12/why-amazon-is-losing-its-battleagainst-chinese-counterfeiters/ (Accessed 3 October 2017).

Sørensen, A.B. (1975), "The structure of intragenerational mobility", American Sociological Review, Vol. 40 No. 4, pp. 456-471.

Steidlmeier, P. (1999), "Gift giving, bribery and corruption: ethical management of business relationships in China", Journal of Business Ethics, Vol. 20 No. 2 pp. 121-132.

Stephens, N.M., Fryberg, S.A., Markus, H.R., Johnson, C. S. and Covarrubias, R. (2012), "Unseen disadvantage: how American universities' focus on independence undermines the academic performance of first-generation college students", Journal of Personality and Social Psychology, Vol. 102 No. 6, pp. 1178-1197.

Stephens, N.M., Markus, H.R. and Phillips, L.T. (2014), "Social class culture cycles: how three gateway contexts shape selves and fuel inequality", Annual Review of Psychology, Vol. 65, pp. 611-634.

Stephens, N.M., Markus, H.R. and Townsend, S.S. (2007), "Choice as an act of meaning: the case of social class", Journal of Personality and Social Psychology, Vol. 93 No. 5, pp. 814-830.

Su, C. and Littlefield, J.E. (2001), "Entering guanxi: A business ethical dilemma in Mainland China?", Journal of Business Ethics, Vol. 33 No. 3 pp. 199-210.

Su, C., Sirgy, M.J. and Littlefield, J.E. (2003), "Is guanxi orientation bad, ethically speaking? A study of Chinese enterprises”, Journal of Business Ethics, Vol. 44 No. 4 pp. 303-312.

Sun, G., D’Alessandro, S. and Johnson, L. (2014), “Traditional culture, political ideologies, materialism and luxury consumption in China", International journal of consumer studies, Vol. 38 No. 6, pp. 578-585.

Swaidan, Z. (2012), "Culture and consumer ethics", Journal of Business Ethics, Vol. 108 No. 2 pp. 201-213. 
Tang, F., Tian, V. and Zaichkowsky, J. (2014), "Understanding counterfeit consumption", Asia Pacific Journal of Marketing and Logistics, Vol. 26 No. 1 pp. 4-20.

Thal, J.S. (2014), "How the demand for wives in South Korea, Singapore, and China is fueling a regional matchmaking trade", available at: http://foreignpolicy.com/2015/03/26/deco derasias-bride-market-wives-south-korea-singapore-china-vietnam/ (accessed 27 September 2017).

Tian, Y. (2011), Fansub cyber culture in China, master's thesis, Georgetown University, Washington, DC.

Tian, K.T., Bearden, W.O. and Hunter, G.L. (2001), “Consumers' need for uniqueness: scale development and validation", Journal of Consumer Research, Vol. 28 No. 1, pp. 50-66.

Vitell, S.J. (2003), "Consumer ethics research: review, synthesis and suggestions for the future", Journal of Business Ethics, Vol. 43 No. 1-2 pp. 33-47

Vitell, S.J. (2015), “A Case for consumer social responsibility (CnSR): Including a selected review of consumer ethics/social responsibility research", Journal of Business Ethics, Vol. 130 No. 4 pp. 767-774.

Walder, A.G. (1995), "Local governments as industrial firms: an organizational analysis of China's transitional economy", American Journal of Sociology, Vol. 101 No. 2, pp. 263301.

Walder, A.G. (1996), "Markets and inequality in transitional economies: toward testable theories", American Journal of Sociology, Vol. 101 No. 4, pp. 1060-1073.

Wang, N. (2010), “从节俭主义到消费主义转型的文化逻辑”, 兰州大学学报（社会科学版）, Vol. 38 No. 3, pp. 14-22.

Wang, Y. (2016), "Why shanghai couples are scrambling to get divorced", available at: https://www.forbes.com/sites/ywang/2016/08/31/shanghai-couples-scrambled-to-divorceto-buy-property/\#4c90842c7a64 (accessed 22 September 2017).

Wang, F., Cai, Y. and Gu, B. (2013), "Population, policy, and politics: how will history judge China's one-child policy?" Population and Development Review, Vol. 38 No. s1, pp.115129.

Wang, Y., Zhang, L., Kong, X., Hong, Y., Cheon, B. and Liu, J. (2016), "Pathway to neural resilience: self-esteem buffers against deleterious effects of poverty on the hippocampus", Human Brain Mapping, Vol. 37 No. 11, pp. 3757-3766.

Warren, D.E., Dunfee, T.W. and Li, N. (2004), "Social exchange in China: The double-edged sword of guanxi”, Journal of Business Ethics, Vol. 55 No. 4 pp. 353-370. 
Wei, C. (2016), “糾結的字幕組:「隱身英雄」遊走法律邊緣”, available at: https://theinitium. com/article/20161018-international-Fansub/ (Accessed 3 October 2017).

Weller, C. (2017), "Chinese 'Taobao villages' are turning poor communities into huge online retail hubs", available at: http://www.businessinsider.com/chinese-taobao-villagesescape-poverty-2017-2 (Accessed 3 October 2017).

Whyte, M.K., Feng, W. and Cai, Y. (2015), "Challenging myths about China's one-child policy”, The China Journal, Vol. 74, pp. 144-159.

Winterich, K.P. and Zhang, Y. (2014), “Accepting inequality deters responsibility: How power distance decreases charitable behavior", Journal of Consumer Research, Vol. 41 No. 2 pp. 274-293.

Witfogel, K.A. (1956), The Hydraulic Civilizations, University of Chicago Press, University of Chicago Press.

Wong, N.Y. and Ahuvia, A.C. (1998), "Personal taste and family face: Luxury consumption in Confucian and Western societies", Psychology \& Marketing, Vol. 15 No. 5 pp. 423-441.

Wu, X. (2002), "Work units and income inequality: the effect of market transition in urban China", Social Forces, Vol. 80 No. 3, pp. 1069-1099.

Wu, X. and Treiman, D.J. (2004). "The household registration system and social stratification in China: 1955-1996”, Demography, Vol. 41 No. 2, pp. 363-384.

Xia, Z.R. (2017), Consumer Culture in China: Consumption Face, Doctoral dissertation, University of Otago, New Zealand.

Xie, Y. and Zhou, X. (2014). "Income inequality in China", Proceedings of the National Academy of Sciences, Vol. 111 No. 19, pp. 6928-6933.

Yoon, S. and Kim, H.C. (2016), "Keeping the American Dream alive: the interactive effect of perceived economic mobility and materialism on impulsive spending", Journal of Marketing Research, Vol. 53 No. 5, pp. 759-772.

Yoon, S. and Kim, H.C. (2017), "Feeling Economically Stuck: The Effect of Perceived Economic Mobility and Socioeconomic Status on Variety Seeking”. Journal of Consumer Research, Vol. 44 No. 5, pp. 1141-1156.

Yu, L. (2014), Consumption in China: How China's New Consumer Ideology is Shaping the Nation. John Wiley \& Sons, New Jersey.

Zeng, Y. and Hesketh, T. (2016), "The effects of China's universal two-child policy”, The Lancet, Vol. 388 No. 10054, pp. 1930-1938.

Zhang, P. and Lin, X. (2014), “制度与观念: 城镇化与农民工家庭的住房消费选择”, 青年研 究, Vol.2, pp. 62-72. 
Zhang, X. (2013), "Fansubbing in China", MultiLingual, Jul-Aug, 30-37.

Zhou, X. (2005), 中国中产阶层调查, 社会科学文献出版社, Shanghai, China.

Zhou, X. (2008), “Chinese middle class: reality or illusion?”, in Jaffrelot, C. and van der Veer, P. (Eds.), Patterns of Middle Class Consumption in India and China, SAGE Publications India, New Delhi, pp. 110-126.

Zhou, X. (2010), “全球化, 社会转型与中产阶级的建构-以中国为对象的比较研究”, 江苏行 政学院学报, Vol. 2010 No. 1, pp. 61-69.

Zhou, X.D., Wang, X.L., Li, L. and Hesketh, T. (2011), "The very high sex ratio in rural China: impact on the psychosocial wellbeing of unmarried men", Social Science \& Medicine, Vol. 73 No. 9, pp. 1422-1427.

Zhou, X., Tuma, N.B. and Moen, P., (1997), "Institutional change and job-shift patterns in urban China, 1949 to 1994”, American Sociological Review, Vol. 62 No. 3, pp. 339-365. 